\title{
Thyroid dysfunction among Indian pregnant women and its effect on the maternal and fetal outcome
}

\author{
Aditi Jain $^{1}$, Raksha M. ${ }^{2 *}$, Kanakalatha D. Nakum ${ }^{1}$ \\ ${ }^{1}$ Department of Obstetrics and Gynaecology, GMSTH Hospital, Bhavnagar, Gujarat, India \\ ${ }^{2}$ Department of Obstetrics and Gynaecology, BCMRI, Gujarat, India
}

Received: 22 January 2021

Revised: 07 February 2021

Accepted: 08 February 2021

\author{
*Correspondence: \\ Dr. Raksha M., \\ E-mail: drraksha.m@gmail.com
}

Copyright: () the author(s), publisher and licensee Medip Academy. This is an open-access article distributed under the terms of the Creative Commons Attribution Non-Commercial License, which permits unrestricted non-commercial use, distribution, and reproduction in any medium, provided the original work is properly cited.

\begin{abstract}
Background: Screening of thyroid disorders in antenatal women during first trimester, to recommend management of thyroid disorder during pregnancy and to know the maternal and fetal outcome of such pregnancy.

Methods: This is a prospective study for the incidence of thyroid disorder in early pregnancy and the outcome of such pregnancy. 100 cases were randomly selected from the antenatal clinic at a tertiary care hospital in India and after fulfilling the inclusion criteria they were subjected to screening for thyroid disorder till 13 weeks of pregnancy. TSH is often considered the "gold standard" for assessing thyroid function. If the participant had normal value then she was not subjected to follow up, but if abnormal, then follow up was done after 4-8 weeks, thyroid profile was repeated and if values were altered, they were medically managed and closely monitored. The obstetric and perinatal outcome of the pregnancy was noted.

Results: In this screening study to detect and manage thyroid disorder, 100 antenatal women were selected randomly, from which 49 women where primigravidae and 51 women were multi-gravidae, 17 of them were of $<20$ years, 54 were between 21 to 25 years. There was 5 percent incidence of thyroid disorder in the study group. There were 3 cases of hyperthyroidism and 2 cases of overt hypothyroidism which had poor fetal and maternal outcome on follow up.

Conclusions: Our study shows that the evaluation of thyroid disorders in early pregnancy and timely intervention will lead to a decrease in the complications thereby improving the maternal and fetal outcome.
\end{abstract}

Keywords: Overt hypothyroidism, Hyperthyroidism, Preterm labour

\section{INTRODUCTION}

The thyroid gland is one of the largest endocrine gland in body, weighing 2-3 grams in neonates and 18-60 grams in adults, and its weight is increased during pregnancy.

The thyroid gland controls rate of use of energy sources, protein synthesis, and controls the body's sensitivity to other hormones. It participates in these processes by producing thyroid hormones, the principal ones being thyroxine (T4) and triiodothyronine (T3), which is more active. These hormones regulate the growth and rate of function of many other systems in the body. T3 and T4 are synthesized from iodine and tyrosine. The thyroid also produces calcitonin, which plays a role in calcium homeostasis. . $^{1,2}$

Hormonal output from the thyroid is regulated by thyroidstimulating hormone (TSH) produced by the anterior pituitary, which itself is regulated by thyrotropin-releasing hormone (TRH) produced by the hypothalamus. ${ }^{3}$

Fetal thyroxine is wholly obtained from maternal sources in early pregnancy since the fetal thyroid gland only becomes functional in the second trimester of gestation. As thyroxine is essential for fetal neurodevelopment it is 
critical that maternal delivery of thyroxine to the fetus is ensured early in gestation. In pregnancy, iodide losses through the urine and the feto-placental unit contribute to a state of relative iodine deficiency. ${ }^{3,4}$ Thus, pregnant women require additional iodine intake. A daily iodine intake of $250 \mu \mathrm{g}$ is recommended in pregnancy but this is not always achieved even in iodine sufficient parts of the world.

Thyroid hormone concentrations in blood are increased in pregnancy, partly due to the high levels of estrogen and due to the weak thyroid stimulating effects of human chorionic gonadotropin (hCG) that acts like TSH. Thyroxine (T4) levels rise from about 6-12 weeks, and peak by mid-gestation; reverse changes are seen with TSH.

Thyroid disease in pregnancy can affect the health of the mother and the child before and after delivery. Thyroid disorders are prevalent in women of child-bearing age and for this reason commonly present as an intercurrent disease in pregnancy and the puerperium. Uncorrected thyroid dysfunction in pregnancy has adverse effects on fetal and maternal well-being. The deleterious effects of thyroid dysfunction can also extend beyond pregnancy and delivery to affect neuro intellectual development in the early life of the child. ${ }^{4}$ Studies have shown an association between overt hypothyroidism and adverse fetal and obstetric outcomes. Maternal complications such as miscarriages, anemia, pre-eclampsia, abruption and postpartum hemorrhage can occur in pregnant women with overt hypothyroidism. ${ }^{5,6}$ Also, the offspring of these mothers can have complications such as premature birth, low birth weight and increased neonatal respiratory distress. ${ }^{6}$ Similar complications have been reported in mothers with subclinical hypothyroidism. A three-fold risk of placental abruption and a two-fold risk of pre-term delivery were reported in mothers with subclinical hypothyroidism. ${ }^{7,8}$

Demand for thyroid hormones is increased during pregnancy which may cause a previously unnoticed thyroid disorder to worsen. More women were diagnosed with thyroid dysfunction when all pregnant women were tested instead of just testing those at 'high-risk' of thyroid problems (those with family history, signs or symptoms). ${ }^{9}$ So, finding more women with thyroid dysfunction we can treat and give proper management throughout their pregnancies. This is the importance of universal screening for thyroid disorders. ${ }^{10}$

It is essential to screen thyroid disorders in antenatal women during first trimester, to recommend management of thyroid disorder during pregnancy and to know the maternal and fetal outcome of such pregnancy.

\section{METHODS}

In our study, screening of 100 antenatal women was conducted in the Department of Obstretics and Gynaecology at a tertiary care hospital, Government medical and Sir Takhtsinhji Hospital in India from September 2015 to July 2016.

\section{Inclusion criteria}

Antenatal women in first trimester till 13 weeks of pregnancy. Age <35 years. Singleton pregnancy. Primigravida or multigravida

\section{Exclusion criteria}

Associated with any medical illness like diabetes mellitus, hypertension, cardiac disease. Multifetal gestation

After obtaining the gestational age and informed consent of antenatal patients in 1st trimester, 100 patients were randomly selected for the study. A detailed history was taken. A thorough general physical examination and local thyroid examination was done. Pregnancy was confirmed by examination, urine pregnancy test and ultrasound.

$2 \mathrm{ml}$ of the fasting blood sample was taken for serum T3, serum T4 and serum TSH estimation. In the laboratory it was analyzed by ELISA test. Due to dynamic changes during pregnancy, use of trimester-specific and assayspecific TSH normal ranges is recommended. Where such reference ranges are not available, the following cutoffs may be used: first trimester, serum $\mathrm{TSH}<2.5 \mathrm{mIU} / \mathrm{L}$, second trimester $<3 \mathrm{mIU} / \mathrm{L}$, third trimester $<3 \mathrm{mIU} / \mathrm{L}$. These were the reference ranges used in our study.

TSH is usually recommended because it can detect abnormalities before other tests become abnormal. When used to confirm suspected disease in patients referred to an endocrine specialty clinic, the TSH test has a sensitivity above 98 percent and a specificity greater than 92 percent for the clinical and functional diagnosis.

If the values were abnormal the pregnant woman was followed up after 4 to 8 weeks and thyroid profile was repeated. If the values were still altered management and close monitoring during pregnancy were done. The obstetric and perinatal outcome of the pregnancy were noted in the women diagnosed with thyroid disorder. Data analysis was done using Statistical package for social sciences (SPSS) software.

\section{RESULTS}

As per the inclusion criteria of our study, a total of 100 antenatal women in the first trimester of pregnancy in age group of 18 to 35 years, without any known medical illness/prior thyroid disorder, with their informed consent were enrolled for the study for the screening of thyroid disorder, hence their blood samples were sent for T3, T4, TSH profile after their detailed history taking and thorough examination. Antenatal women with altered thyroid profile were followed up with medical management to have control of the disorder and also to know the outcome of pregnancy. 
Table 1: Obstetric index of the study participants.

\begin{tabular}{|ll|}
\hline Obstetric index & $\begin{array}{l}\text { Total } 100 \text { antenatal } \\
\text { women }\end{array}$ \\
\hline Primigravida & 49 \\
\hline Multigravida & 51 \\
\hline
\end{tabular}

Table1 shows that out of the 100 antenatal women selected randomly, 49 were primigravida and 51 were multigravida.

17 of them were less than 20 years old, 54 were between 21 to 25 years, 28 were between 26 to 30 and only 1 woman was between 31 to 35 as seen in table 2 .

Table 3 shows that out of the 100 antenatal women that we screened there were 5 women with thyroid disorders, which means that the incidence of thyroid disorder in the study group was 5 percent. The rest of the antenatal women had their thyroid profile within normal limits and hence where not subjected to follow up. From the 5 cases of thyroid disorder, there were 3 cases of hyperthyroidism and 2 cases of overt hypothyroidism.

Table 2: Age groups to which the participants belonged.

\begin{tabular}{|l|l|}
\hline Age (in years) & Number of participants \\
\hline$<\mathbf{2 0}$ & 17 \\
\hline $\mathbf{2 1}$ to 25 & 54 \\
\hline $\mathbf{2 6}$ to 30 & 28 \\
\hline $\mathbf{3 1}$ to 35 & 01 \\
\hline
\end{tabular}

Table 3: Number of cases with thyroid disorder.

\begin{tabular}{|ll|}
\hline Thyroid disorder & Total cases out of $\mathbf{1 0 0}$ \\
\hline Hypothyrodism & 02 \\
\hline Hyperthyroidism & 03 \\
\hline
\end{tabular}

Table 4: cases with abnormal thyroid function and their outcome.

\begin{tabular}{|c|c|c|c|c|}
\hline $\begin{array}{l}\text { Case } \\
\text { no. }\end{array}$ & $\begin{array}{l}\text { Obstetric } \\
\text { history }\end{array}$ & Mode of delivery & $\begin{array}{l}\text { Gestational } \\
\text { weeks }\end{array}$ & Outcome \\
\hline 1 & G3A2 & $\begin{array}{l}\text { Spontaneous preterm } \\
\text { delivery }\end{array}$ & 32 weeks & $\begin{array}{l}\text { Female baby of } 2 \mathrm{~kg} \text {-preterm admitted to } \\
\text { NICU }\end{array}$ \\
\hline 2 & G4P1L1A2 & $\begin{array}{l}\text { Induction of labour, } \\
\text { vaginal delivery }\end{array}$ & 28weeks & $\begin{array}{l}\text { Development of severe pre-eclampsia in } \\
\text { mother and early pre-term induction was } \\
\text { done. Female baby of } 900 \mathrm{gms} \text {, but did not } \\
\text { survive in NICU. }\end{array}$ \\
\hline 3 & G4A3 & Spontaneous abortion & 10 Weeks & Spontaneous complete abortion. \\
\hline 4 & G3P2L2 & First trimester MTP & 12 Weeks & $\begin{array}{l}\text { Patient developed hyperemesis gravidarum, } \\
\text { intractable vomiting not relieved with } \\
\text { medications. }\end{array}$ \\
\hline 5 & G5P4L4 & $\begin{array}{l}\text { Spontaneous preterm } \\
\text { labour }\end{array}$ & 30weeks & $\begin{array}{l}\text { Patient had abruption, delivered a fresh still } \\
\text { born baby of weight } 1.8 \mathrm{~kg} \text {. }\end{array}$ \\
\hline
\end{tabular}

\section{DISCUSSION}

Table 4 shows the obstetric index, mode of delivery, period of gestation and the outcome of pregnancy in each of the 5 cases with abnormal thyroid profile.

The first detected case of overt hypothyroidism was a 25 year old third gravida with history of two abortions. She presented with history of weight gain, lethargy, oligomenorrhoea with irregular menstrual cycle before conception, slight enlargement of thyroid gland focally without any positive family history. Her vitals were within normal limits. After her screening she was diagnosed with overt hypothyroidism with an elevated TSH and both T3, T4 decreased below the normal limits of first trimester of pregnancy. She was then started with Levo-Thyroxine $25 \mu \mathrm{gm}$ and followed up after 4 weeks, the report of which was still abnormal, hence dosage was increased to $50 \mu \mathrm{gm}$.
She went into spontaneous pre-term labour at 32 weeks of pregnancy and delivered a preterm female baby weighing $2 \mathrm{~kg}$. The baby required NICU admission. All other causes for preterm labour like UTI, anemia etc were ruled out. Preterm labour is a very common antenatal complication due to altered thyroid profile in antenatal period, leading to increasing perinatal mortality and morbidity. Study by Haddow et al showed a higher prevalence of subclinical hypothyroidism in women with pre-term delivery (before 32 weeks) compared to matched controls delivering at term. ${ }^{1}$ An association with adverse obstetrics outcome has also been demonstrated in pregnant women with thyroid autoimmunity independent of thyroid function. Treatment of hypothyroidism reduces the risks of these adverse obstetric and fetal outcomes.

The second detected case was a 28 year old G4P1L1A2 with 13 weeks of pregnancy. She presented with history of 
weight loss, palpitations, hot flushes at times, pedal edema and occasional diarrhea since 1 month, her pulse rate was 110/min and B.P 130/80 $\mathrm{mm}$ of $\mathrm{Hg}$ at first visit. After her screening report she was diagnosed with hyperthyroidism for which PTU (propylthiouracil) was started, her profile was repeated every 4 weekly but it remained altered as patient discontinued medication despite repeated instructions. She developed pedal edema with severe preeclampsia, B.P $160 / 110 \mathrm{~mm}$ of $\mathrm{Hg}$ at 28 weeks of pregnancy with exopthalamos and ascitis, hence the decision for termination of pregnancy was taken at 28 weeks. With informed consent of the patient and relatives induction of labour was done and patient delivered a female baby of 900 gms, which expired within 4 hours after birth in the NICU.

Hyperthyroidism during the earlier weeks of pregnancy leads to severe maternal as well as fetal complications leading to increasing hospital admissions and perinatal mortality. These antenatal complications can be prevented by earlier diagnosis and treatment, leading to improvement in maternal and fetal outcome.

Study by Henrichs et al stated the risk of low birth weight infants was 0.74 among controlled women, 2.36 among women who were controlled during pregnancy, and 9.24 among women who were uncontrolled during pregnancy compared to the incidence among non-hyperthyroid mothers. $^{3}$ The risk of severe preeclampsia was significantly higher among uncontrolled women compared with those who were controlled during their pregnancies. Elevated TSH-receptor antibody levels were not related to preeclampsia. Maternal thioamide therapy did not adversely affect neonatal outcomes. Lack of control of hyperthyroidism significantly increases the risk of low birth weight infants and severe preeclampsia

The third case was a 28 year old G4 with no previous history of live births, having 3 recurrent abortions in early first trimester since 4 years. She came with 6 weeks of amenorrhoea and complains of anxiety, palpitations, weight loss and facial puffiness since one month. When she was subjected to screening as per the protocol of our study, she was diagnosed with hyperthyroidism and was started with PTU, 4 weeks later her profile was repeated, which was still altered. She developed spotting P/V and then spontaneous abortion at 10 weeks of pregnancy.

The study by Amit et al in Indian journal of obstetrics and gynecology on hypothyroidism in pregnancy reported that the Incidence of hypothyroidism in pregnancy was $1.15 \%$ and proved that hypothyroidism is common problem in recurrent pregnancy loss. ${ }^{4}$ Severe maternal hypothyroidism early in gestation is strongly associated with fetal distress in labour. Also early adequate replacement therapy is especially prudent in women presenting with severe hypothyroidism to have successful pregnancy outcome. The relative high occurrence of hypothyroidism in women with pregnancy, the possible role of thyroid functional disorders in etiology of at least some part of recurrent spontaneous abortions and based on our results association. Between spontaneous abortion and overt hypothyroidism, had emphasized the importance of thyroid functions tests mainly serum TSH for screening routine in all pregnancies. Careful monitoring and control of hypothyroidism during pregnancy and intrapartum period is necessary, since these patients are at increased risk of developing fetal distress during labour. Hence routine TSH should be evaluated as a way to potentially improve pregnancy outcome and maternal well being.

The fourth case, was a 28 year old G3P2L2 with 12 weeks of pregnancy. She presented with chief complains of severe vomiting, palpitations, sunken eyes, dry coated tongue, loss of appetite and tachycardia. She was dehydrated. She was admitted and basic resuscitative measures such as fluid therapy, injectable antiemetics were given, after which all the basic investigations to rule out the causes of intractable vomiting were conducted. Finally, in the screening test she was diagnosed with hyperthyroidism for which PTU was started, but still due to hyperemesis gravidarum and patient insisting on MTP her pregnancy was terminated at 12 weeks.

The fifth case, was a 32 year old G5P4L4 with 13 weeks of pregnancy with complains of spotting $\mathrm{P} / \mathrm{V}$, headache, weight gain and focal enlargement of the thyroid gland since one month. After her screening test she was diagnosed to have overt hypothyroidism, for which tablet Levo-thyroxine was started in a dose of $50 \mu \mathrm{gm}$. Her thyroid profile was repeated every 4th weekly, the dose was altered to $150 \mu \mathrm{gm}$ per day after repeated testing. At 30 weeks period of gestation she came in labour with abruption and intra uterine fetal demise. The vitals on admission were normal. She had a preterm vaginal delivery and delivered a fresh still born baby weighing 1.8 $\mathrm{kg}$.

Leung et al. demonstrated a $22 \%$ risk of gestational hypertension in pregnant women with $\mathrm{OH}$, it is higher than for euthyroid women or those with subclinical hypothyroidism ( $\mathrm{SH}$ ) Gestational hypertension-namely, eclampsia, preeclampsia, and pregnancy-induced hypertension-was significantly more common in the overt and subclinical hypothyroid patients than in the general population, $36 \%$ of the overt and $25 \%$ of the subclinical hypothyroid subjects who remained hypothyroid at delivery developed gestational hypertension. ${ }^{6}$ Low birth weight in both overt and subclinical hypothyroid patients was secondary to premature delivery for gestational hypertension. Normalization of thyroid function tests may prevent gestational hypertension and its attendant complications in hypothyroid patients.

Thus by the above discussed cases, we can say that all these antenatal complications like preterm vaginal delivery, abruption with intra uterine fetal demise and development of severe pre-eclampsia are commonly associated complications of altered thyroid profile in earlier weeks of pregnancy which can be minimized with 
timely screening, diagnosis and management of the thyroid disorder, thereby preventing complications in both the mother and the fetus.

As the small sample size of our study was small this was a limitation of the present study. Limiting thyroid testing only to early pregnancy would miss a significant proportion of those indicated for endocrine care. More comprehensive screening of thyroid autoimmunity and dysfunction seems warranted.

\section{CONCLUSION}

Maternal hypothyroidism during first trimester (either subclinical or manifest) is known to cause impaired neuropsychomotor development and reduced mean IQ score in children.

Maternal thyroid disorders will lead to low IQ babies and will also lead to various maternal and fetal complications like: pregnancy induced hypertension and pre-eclampsia, abruptio placentae, chances of recurrant abortion/ bad obstetric history, intrauterine fetal death, preterm delivery, low birth weight babies and persistent hypothyroidism at 12 weeks gestation was associated with an 8-10 point deficit in mental and motor function scores in infant offspring compared to children of mothers with normal thyroid function.

In our study there was a 5 percent incidence of thyroid disorders, 5 out of the 100 women selected had thyroid disorder, for which treatment and follow up of pregnancy outcome was done. Rest of the 95 antenatal women with normal thyroid profile and were not subjected to follow up. Out of the 5, there were 2 cases of hypothyroidism and 3 cases of hyperthyrodisim, leading to poor fetal and maternal outcome. One case had spontaneous pre-term delivery at 32 weeks and the baby required NICU admission. Another case had abruption with intrauterine fetal demise at 30 weeks. One of the cases developed severe pre-eclampsia with ascitis, so termination of pregnancy was carried out. One case had spontaneous incomplete abortion at 10 weeks of gestation while our last case underwent first trimester MTP at 12 weeks of gestation.

As it is now well known that different thyroid abnormalities in the mother during her antenatal period /post partum period will not only effect adversely the mother alone but also extend to affect the neuropsycological development of the child as well, universal screening for thyroid disorders even in the low risk groups is mandatory as it helps to pick up the disorder early and treat effectively at the earliest so as to reduce the maternal and fetal mortality as well as morbidity.

Our study also emphasizes on the concept of universal screening as the alternative would be missing out on $1 / 3 \mathrm{rd}$ of the pregnancies with a thyroid disorder that go unnoticed and untreated among the general low risk group of population which would lead finally to a vicious cycle of uncontrolled thyroid abnormality, poor maternal and fetal outcome.

Funding: No funding sources

Conflict of interest: None declared

Ethical approval: The study was approved by the Institutional Ethics Committee

\section{REFERENCES}

1. Haddow JE, Palomaki GE, Allan WC, Williams JR, Knight GJ, Gagnon J, et al. Maternal thyroid deficiency during pregnancy and subsequent neuropsychological development of the child. N Engl J Med.1999;341(8):549-55.

2. Victor J. Pop, Johannes L. Kuijpens, Van Baar AL, Verkerk G, Van Son MM , J J de Vijlder, et al. Low maternal free thyroxine concentrations during early pregnancy are associated with impaired psychomotor development in infancy. Clin Endocrinol 1999;50(2):149-55.

3. Henrichs J, Jacoba J Bongers-Schokking, Schenk JJ, Ghassabian A, Schmidt HG, Visser TJ. Maternal Thyroid Function during Early Pregnancy and Cognitive Functioning in Early Childhood. The Generation R Study, J Clin Endocrinol Metab. 2010;95(9):4227-34.

4. Amit R. Barapatre, Seema Vaidya. Study of thyroid profile in patients with recurrent abortions. J Evol Med Den Sci. 2013;2(49):9614-620.

5. Glinoer D, Soto MF, Bourdoux P, Lejeune B, Delange F, Lemone M. Pregnancy in patients with mild thyroid abnormalities: maternal and neonatal repercussions. J Clin Endocrinol Metab. 1991;73(2):421-7.

6. Leung, Anna S Millar, Koonings PP, Montoro L, Mestman JH. Perinatal Outcome in Hypothyroid Pregnancies. Obstet Gynecol. 1993;81(3):349-53.

7. N Benhadi, Wiersinga WM, Reitsma JB, Vrijkotte TGM, Bonsel GJ. Higher maternal TSH levels in pregnancy are associated with increased risk for miscarriage, fetal or neonatal death; Eur J Endocrinol. 2009;160(6):985-91.

8. Millar, Lynnae K Wing, Deborah A, Koonings PP, Montoro MN, Mestman JH. Low Birth Weight and Preeclampsia in Pregnancies Complicated by hyperthyroidis. Obstet Gynecol. 1994;84(6):946-9.

9. Nuzhat A, Pranathi R, Evita F. Hypothyroidism in pregnancy: Is universal screening needed? J Obstet Gynecol India. 2006;56(6):495-98.

10. Horacek J, Spitalnikova S, Dlabalova B, Malirova E, Vizda J, Svilias I. Universal screening detects twotimes more thyroid disorders in early pregnancy than targeted high-risk case finding. Eur J Endocrinol. 2010;163(4):645-50.

11. Vaidya B, Anthony S, Bilous M, Shields B, Drury J, Hutchison S, et al. Detection of Thyroid Dysfunction in Early Pregnancy: Universal Screening or Targeted 
High-Risk Case Finding? J Clin Endocrinol Metab. 2007;92(1):203-7.

12. Ghassabian A, Bongers-Schokking JJ, de Rijke YB, van Mil N, Jaddoe VWV et al. Maternal Thyroid Autoimmunity During Pregnancy and the Risk of Attention Deficit/Hyperactivity Problems in Children. The Generation R Study: Thyroid. 2012;22(2):17886.

13. Abalovich M, Gutierrez S, Alcaraz G, Maccallini G, Garcia A, Levalle O. Overt and Subclinical Hypothyroidism Complicating Pregnancy. Thyroid. 2002;12(1):63-8.

14. Negro R, Schwartz A, Gismondi R, Tinelli A, Mangieri T, Stagnaro-Green A. Increased Pregnancy Loss Rate in Thyroid Antibody Negative Women with TSH Levels between 2.5 and 5.0 in the First Trimester of Pregnancy. J Clin Endocrinol Metab. 2010;95(9).

15. Modesto T, Tiemeier H, Robin P Peeters, Vincent W V Jaddoe, Hofman A. Maternal Mild Thyroid Hormone Insufficiency in Early Pregnancy and Attention Deficit/Hyperactivity Disorder Symptoms in Children. JAMA Pediatr. 2015;169(9):838-45.

16. Das V, Mittal S, Agarwal A, Sahu M. Overt and subclinical thyroid dysfunction among Indian pregnant women and its effect on maternal and fetal outcome. Arch Gynecol Obstet. 2010;281(2):215-20.

17. Vaidya B, Anthony S, Bilous M, Shields B, Drury J, Hutchison $S$ et al. Detection of Thyroid Dysfunction in Early Pregnancy: Universal Screening or Targeted High-Risk Case Finding? J Clin Endocrinol Metab. 2007;92(1):203-7.

18. Negro R, Schwartz A, Gismondi R, Tinelli A, Mangieri T, Stagnaro-Green A. Universal Screening Versus Case Finding for Detection and Treatment of Thyroid Hormonal Dysfunction During Pregnancy. J Clin Endocrinol Metab 2010;95(4):1699-707.

19. Spencer L, Bubner T, Bain E, Middleton P. Screening and subsequent management for thyroid dysfunction pre-pregnancy and during pregnancy for improving maternal and infant health. Cochrane Database Syst Rev. 2015;(9):CD011263.

20. Casey BM, Dashe JS, Wells CE, McIntire DD, Byrd W, Leveno KJ. Subclinical Hypothyroidism and Pregnancy Outcomes. Obstet Gynecol. 2005;105(2):239-45.

21. Thung SF, Funai EF, Grobman WA. The costeffectiveness of universal screening in pregnancy for subclinical hypothyroidism. Am J Obstet Gynecol. 2009;200(3):267.e1-7.

22. Donny LF, Chang, Pearce EN. Screening for Maternal Thyroid Dysfunction in Pregnancy: A Review of the Clinical Evidence and Current Guidelines. J Thyroid Res. 2013;2013:851326.

23. Berbel P, Francisco JB, del Rey E, de Escobar GM. Iodine supplementation during pregnancy: a public health challenge. Trends Endocrinol Metab. 2007;18(9):338-43.

24. N K Kuşcu, F Koyuncu. Hyperemesis gravidarum: current concepts and management. Postgrad Med J. 2002;78(916):76-9.

25. Najafipour $\mathrm{Fa}$, Ghoddousi $\mathrm{Kb}$, Zareizadeh $\mathrm{Mb}$, Fardiazar Zb. Int Evaluation of Thyroid Funtion Tests in Patients with Hyperemesis Gravidarum. J Endocrinol Metab. 2007;5(1):e94595.

26. Wu MQ, Liu J, Wang YQ. Ying Yang, Chong-Huai Yan , Jing Hua. The Impact of Subclinical Hypothyroidism on Adverse Perinatal Outcomes and the Role of Thyroid Screening in Pregnancy. Front Endocrinol (Lausanne). 2019;10:52.

27. Dosiou C, Barnes J, Schwartz A, Negro R, Crapo L, Stagnaro-Green A. Cost-effectiveness of universal and risk-based screening for autoimmune thyroid disease in pregnant women. J Clin Endocrinol Metab. 2012;97(5):1536-46.

28. Han Y, Mao LJ, Kung GXK, Yan SQ, Ren LL. Thyroid autoantibodies in pregnancy are associated with hypertensive disorders of pregnancy: Ma'anshan Birth Cohort Study. Clin Endocrinol (Oxf). 2018;88(6):928-35.

29. Casey BM, Dashe JS, Wells CE, McIntire DD, Leveno KJ, Cunningham GF. Subclinical hyperthyroidism and pregnancy outcomes. Obstet Gynecol. 2006;107:337-41.

30. Idris I, Srinivasan R, Simm A, Page RC. Maternal hypothyroidism in early and late gestation: effects on neonatal and obstetric outcome. Clin Endocrinol (Oxf). 2005;63(5):560-5.

31. Lazarus JH, Minerva. Thyroid disease in pregnancy and childhood. Endocrinol. 2005;30(2):71-87.

32. Taylor PN, Okosieme OE, Premawardhana L, John H Lazarus. Should all women be screened for thyroid dysfunction in pregnancy? Womens Health (Lond). 2015;11(3):295-307.

33. Sepasi F, Rashidian T, Shokri M, Badfar G, Kazemi F, Azami M. Thyroid dysfunction in Iranian pregnant women: a systematic review and meta-analysis. BMC Pregnancy Childbirth. 2020;20(1):405.

34. Gui J, Xu W, Zhang J. Association between thyroid dysfunction and perinatal outcomes in women with gestational hypertension: a retrospective study. BMC Pregnancy Childbirth. 2020;20(1):119.

35. Lai H, Zhan ZY, Liu H. Association between thyroid hormone parameters during early pregnancy and gestational hypertension: a prospective cohort study. J Int Med Res. 2020;48(2).

Cite this article as: Jain A, Raksha M, Nakum KD. Thyroid dysfunction among Indian pregnant women and its effect on the maternal and fetal outcome. Int J Reprod Contracept Obstet Gynecol 2021;10:893-8. 